\title{
Microalgae cultivation for phenol removal from wastewater
}

\begin{abstract}
Phenol is one of most hazardous and toxic pollutants found in industrial wastewater. Biological methods, using bacteria, have been successfully used for the removal of phenols. However, the produced biomass in this case does not have any obvious economic value, and in most cases the bacteria used are pathogenic. By utilizing microalgae instead, the biomass can then be used to produce biodiesel and other valuable products, such as proteins and pigments. In this work, two strains of microalgae, namely Chlorella Sp. and Tetraselmis $s p$. were used for the removal of phenol from synthesized wastewater. Both strains were effective in removing the phenol, with optimum performance at initial phenol concentration of $250 \mathrm{ppm}$.
\end{abstract}

Volume 3 Issue 6 - 2017

\author{
Mohamed Abujayyab, Sulaiman Al-Zuhair \\ Chemical Engineering Department, UAE University, UAE
}

Correspondence: Sulaiman Al-Zuhair, Chemical Engineering Department, UAE University, I555 I Al-Ain, UAE, Tel +97 |37 I3 5319.Email s.alzuhair@uaeu.ac.ae

Received: November 06, 2017 | Published: November 15, 2017

Keywords: wastewater treatment, phenol, chlorella $\mathrm{sp}$, tetraselmis $\mathrm{sp}$, substrate inhibition

\section{Introduction}

Environmental pollution, which increased exponentially during the past several years, is considered one of the main problems facing humanity. Phenol is the primary hazardous pollutant found in the wastewater many industries. ${ }^{1}$ Phenol compound consists of a hydroxy group attached to a benzene ring. It is a colorless compound, soluble in both organic solvents and water, and enters the environment naturally or artificially as a major pollutant. It is a basic structure unit used in several industries, and it is produced from the combustion of coal wood and municipal solid waste, and from oil refineries and pharmaceutical and coke industries..$^{2-4}$ In nature, the sources of phenol include forest, plants, and rangeland fires. ${ }^{5}$ Phenol has harmful effects on aquatic life and ecosystems, and has been noted in surface water, groundwater, drinking water, rainwater, waste sites, sediments, and industrial runoff. The presence of phenol in ground water is related to its rapid filtration through the soil and poor adhesion to soil particles. Phenol could be fatal by ingestion, inhalation, or skin absorption, since it quickly penetrates the skin and may cause severe irritation to the eyes and the respiratory tract. It is listed among the priority organic pollutants by the US Environmental Protection Agency. ${ }^{6}$ Phenol is also considered to be potentially carcinogenic to humans and may be lethal to fish at concentrations of $5-25 \mathrm{gm}^{-3} .^{7}$ It is essential, therefore, that phenol concentration in water effluents be reduced to environmentally acceptable and harmless levels. Several techniques were used to remove phenols from wastewater, including thermal decomposition, adsorption, advanced oxidation method, and electro coagulation. These methods either suffer from low efficiency, or have other disadvantages, such as producing secondary pollutants. ${ }^{8}$ Biological methods, using bacteria, have also been tested for the removal of phenol from wastewater, which showed very promising results. ${ }^{8}$ Nevertheless, the release of these bacteria could cause diseases in plants and depletion of fish stocks, and may also have the potential to cause diseases to humans. ${ }^{9}$ It would be advantageous therefore to use other types of microorganisms, which are less harmful, if they show comparable performance. In addition, the grown bacteria do not have any obvious value. If phenol can be removed by microalgae, the produced biomass in this case can be readily used to produce lipids that can be used for biodiesel production.

\section{Results and discussions}

Two strains of microalgae, namely Chlorella sp. and Tetraselmis $s p$., obtained from a local marine research center in Umm Al-Quwain, UAE, were grown in Bold Bassel medium $(3 \mathrm{~N}-\mathrm{BBM})^{10}$ containing different concentrations of phenol (150-350ppm), as the sole carbon source. The growth mixtures were placed in shaking water bath (LabTech, DaihanlabTech Co. 1td., Koreas) set at $30^{\circ} \mathrm{C}$ and $70 \mathrm{rpm}$ and subjected to high illumination by four LED lights. At regular intervals, aliquots were withdrawn, and the biomass content was determined from the optical density measured at $680 \mathrm{~nm}$ using UV-spectrophotometer (UV-1800, Shimadzu, Japan). The biomass was then removed by centrifugation at $6000 \mathrm{rpm}$ for $10 \mathrm{~min}$ using multispeed centrifuge (IEC CL31, Thermo Scientific, USA), and the phenol concentration in the supernatant was determined using a calibrated high-performance liquid chromatography, HPLC (Shimadzu, Japan). All experiments were carried out in duplicates, and the results presented are the average values. To eliminate any other reason which could also contribute to the drop in phenol concentration, the experiment was repeated at identical condition, except with absence of microalgae. A negligible drop in phenol concentration was observed, which proves that the drop was mainly biological by the microalgae. The drop in phenol concertation and the biomass growth were determined for both strains, and the results were used to determine the rate of phenol removal and specific growth rate, as shown in Figures $1 \& 2$, for Chlorella sp. and Tetraselmis sp., respectively. The performance of both strains was very close, both growing well in media of high concentrations of phenol, with a good ability to degrade the phenol. It was found the growth rate of microalgae, and the phenol drop rate, increased as concentration of phenol increased until the latter reached $250 \mathrm{ppm}$. After that, both growth degradation rates decreased suggesting the effect of substrate inhibition of phenol. 


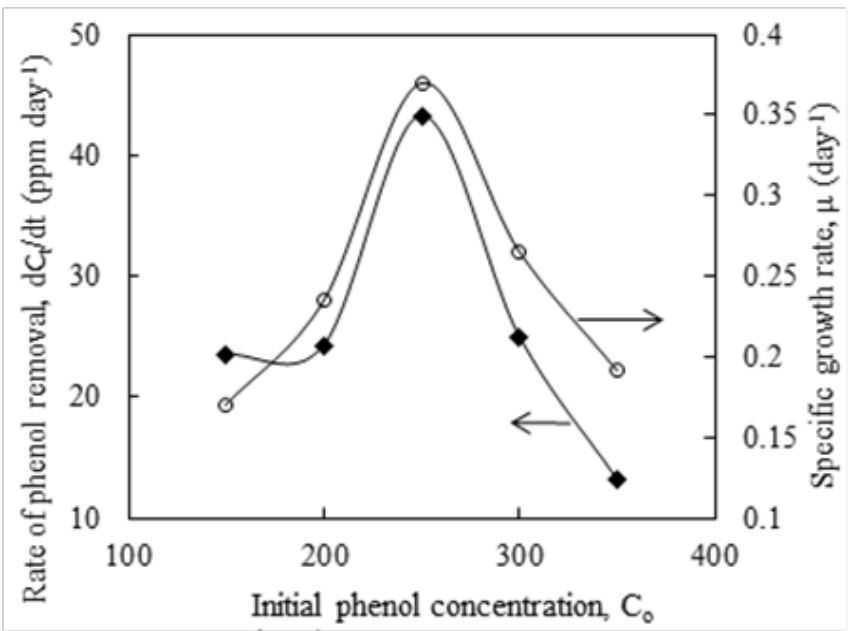

Figure I Phenol removal rate and specific growth rate of Chlorella sp.

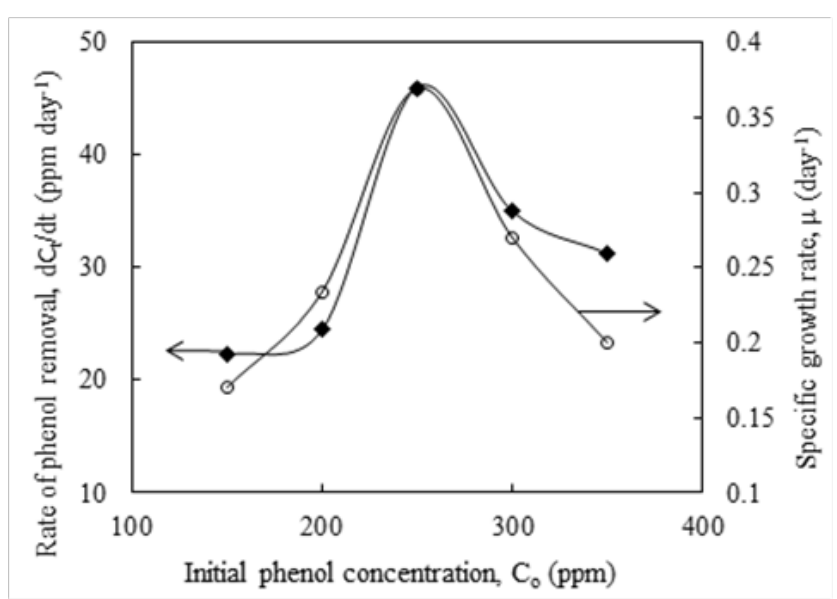

Figure 2 Phenol removal rate and specific growth rate of Tetraselmis sp.

\section{Conclusion}

The ability of two strains of microalgae, namely Chlorella $s p$. and Tetraselmis sp., to grow in phenol containing media and to degrade the phenol have been tested at different concentrations in the range of 150 to $350 \mathrm{ppm}$. Both strains were equally capable of growing and degrading the phenol, with optimum growth and phenol degradation taking place at initial phenol concentration of $250 \mathrm{ppm}$. Using the microalgae for the degrading phenol combines the advantage of using benign microorganisms with producing biomass of important industrial applications.

\section{Acknowledgements}

The authors would like to acknowledge the financial support provided by the Emirates Center for Energy and Environment Research (Fund No. 31R070).

\section{Conflict of interest}

The author declares no conflict of interest.

\section{References}

1. Fang HHP, Chen T, Li YY, et al. Degradation of phenol in wastewater in an upflow anaerobic sludge blanket reactor. Water Research. 1996;30(6):1353-1360.

2. Al-Muhtaseb AH, Khraisheh M. Photocatalytic removal of phenol from refinery wastewater: catalytic activity of $\mathrm{Cu}-$ doped titanium dioxide. Journal of Water Process Engineering. 2015;8:82-90.

3. Estrada Arriaga EB, Zepeda Aviles JA, García-Sánchez L. Posttreatment of real oil refinery effluent with high concentrations of phenols using photo-ferrioxalate and Fenton's reactions with membrane process step. Chemical Engineering Journal. 2016;285:508-516.

4. Lu BL, Qi L, Li MX. Effects of temperature on the growth and product accumulation of Chlorella sp. Advanced Material Research. 2013;712-715:428-432.

5. Wang Y, Tian Y, Han B, et al. Biodegradation of phenol by free and immobilized Acinetobacter sp. strain PD12. J Environ Sci. 2007;19(2):222-225.

6. Kumar A, Kumar S, Kumar S. Biodegradation kinetics of phenol and catechol using Pseudomonas putida MTCC 1194. Biochemical Engineering Journal. 2005;22(2):151-159.

7. Nuhoglu A, Yalcin B. Modeling of phenol removal in a batch reactor. Process Biochemistry. 2005;40(3-4):1233-1239.

8. Jiang H, Fang Y, Fu Y, et al. Studies on the extraction of phenol in wastewater. Journal of Hazardous Materials. 2003;101(2):179-190.

9. Christenson L, Sims R. Production and harvesting of microalgae for wastewater treatment, biofuels, and bioproducts. Biotechnol Adv. 2015;29(6):686-702.

10. Taher $\mathrm{H}, \mathrm{Al}-\mathrm{Zuhair} \mathrm{S}$, AlMarzoqui A, et al. Growth of microalgae using $\mathrm{CO}_{2}$ enriched air for biodiesel production in supercritical $\mathrm{CO}_{2}$. Renewable Energy. 2015;82:61-7. 